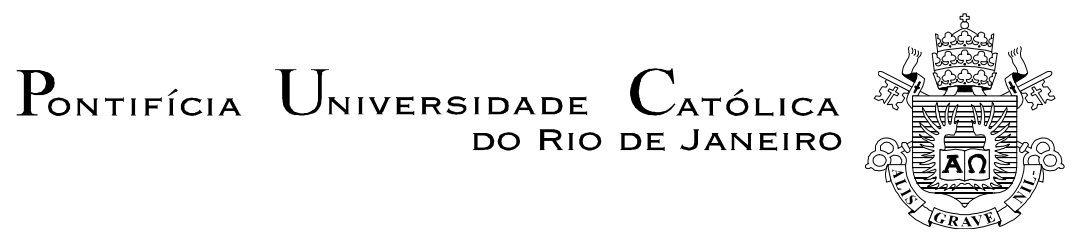

Cláudio de Assumpção Guimarães

\title{
ELEMENTOS TEÓRICOS PARA O ENSINO DA LITERATURA
}

Dissertação de Mestrado

Dissertação apresentada ao Programa de Pós-graduação em Letras da PUCRio como requisito parcial para obtenção do grau de Mestre em Letras.

Orientadora: Prof. ${ }^{\text {D }}$ Dr. ${ }^{a}$ Heidrun Krieger Olinto

Rio de Janeiro julho de 2007 


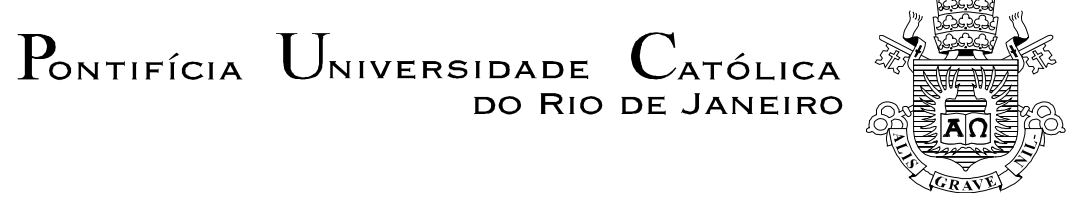

Cláudio de Assumpção Guimarães

\section{ELEMENTOS TEÓRICOS PARA O ENSINO DA LITERATURA}

Dissertação apresentada como requisito parcial para obtenção do grau de Mestre pelo programa de Pós-Graduação em Letras do Departamento de Letras do Centro de Teologia e Ciências Humanas da PUC-Rio. Aprovada pela Comissão Examinadora abaixo assinada.

Profa. Heidrun Friedel Krieger Olinto de Oliveira

Orientadora

Departamento de Letras - PUC-Rio

Prof. Reuber Gerbassi Scofano

UFRJ

Prof. Daniela Beccaccia Versiani

UNESA

Prof. Paulo Fernando Carneiro de Andrade Coordenador Setorial do Centro de Teologia

e Ciências Humanas - PUC-Rio

Rio de Janeiro, de de 
Todos os direitos reservados. É proibida a reprodução total ou parcial do trabalho sem autorização da universidade, do autor e da orientadora.

\section{Cláudio de Assumpção Guimarães}

Graduou-se em Letras na U.F.R.J (Universidade Federal do Rio de Janeiro) em 1986. Especializou-se em Teoria da Literatura pela U.E.R.J (Universidade Estadual do rio de Janeiro) em 1991 e em Informática Educativa pela Faculdade Carioca. Participou de congressos e de diversos cursos no Centro de Estudos Real Gabinete Português de Leitura.

Ficha catalográfica

Guimarães, Cláudio de Assumpção

Elementos teóricos para o ensino da literatura / Cláudio de Assumpção Guimarães ; orientadora: Heidrun Krieger Olinto. - 2007

$98 \mathrm{f.} ; 30 \mathrm{~cm}$

Dissertação (Mestrado em Letras)-Pontifícia Universidade Católica do Rio de Janeiro, Rio de Janeiro, 2007. Inclui bibliografia

1. Letras - Teses. 2. Literatura. 3. Ensino. 4. História literária. I. Olinto, Heidrun Krieger. II. Pontifícia Universidade Católica do Rio de Janeiro. Departamento de Letras. III. Título.

CDD: 800 
Fere de leve a frase... E esquece... Nada Convém que se repita...

Só em linguagem amorosa agrada A mesma coisa cem mil vezes dita.

( Mario Quintana )

À Luciana, Mariana, Gabriela e À Dinda Maria. 


\section{AGRADECIMENTOS}

$\mathrm{O}$ meu eterno carinho

À Prof ${ }^{a}$. Dra ${ }^{a}$. Heidrun Krieger Olinto pelo acolhimento.

Ao $\operatorname{Prof}^{\mathrm{o}} \operatorname{Dr}^{\mathrm{o}}$. Reuber Gerbassi Scofano.

À Prof ${ }^{\mathrm{a}}$. Dr ${ }^{\mathrm{a}}$. Daniela Beccaccia Versiani.

Aos Professores Doutores do Mestrado, Júlio Diniz e Eliana Yunes.

Ao Diretor do Colégio Recanto, Ronaldo Limoeiro.

Às Diretoras da Escola Parque, Mary Ferraz Soares Lopes, Patrícia Konder Lins e Silva e

Rita Barbosa Coutinho.

À coordenadora Roberta Fiani.

À minha família pela paciência e pelas horas roubadas.

À dinda Maria pelo incentivo.

À Mariana Maia Simoni.

À Stella Caymmi.

Ao professor Mauro César Neves Gonzaga.

Ao professor Bráulio Fernandes.

À Sonia Maria. 


\section{Resumo}

Guimarães, Cláudio de Assumpção; Olinto, Heidrun Krieger. Elementos teóricos para o ensino da literatura. Rio de Janeiro,2007. 98p. Dissertação de Mestrado - Departamento de Letras, Pontifícia Universidade Católica do Rio de Janeiro.

A presente dissertação de mestrado, Elementos teóricos para o ensino da literatura, tem por objetivo uma compreensão do fenômeno literário que transcende a sua configuração textual, em vista de uma atualização do ensino da literatura em escolas de Nível Médio. Para alcançar este fim, a pesquisa analisa ferramentas teóricas desenvolvidas pela Estética da Recepção e pela chamada Ciência Empírica da Literatura, avaliando a oportunidade de transferir os seus modelos para o espaço escolar, como estratégia pedagógica inovadora capaz de revigorar o próprio ensino. Neste sentido, a dissertação pretende oferecer caminhos de mediação entre uma tradição ainda vigente e propostas de renovação no campo da didática com respeito ao fenômeno literário e suas formas de historiografia.

\section{Palavras-chave:}

Literatura, Ensino, História Literária 


\section{Abstract}

Guimarães, Cláudio de Assumpção; Olinto, Heidrun Krieger (Advisor). Theoretical elements on literature teaching. Rio de Janeiro,2007. 98p. Dissertation de Mestrado - Departamento de Letras, Pontifícia Universidade Católica do Rio de Janeiro.

The present M.A. thesis, Theoretical elements on literature teaching, aims at understanding the literary phenomenon which transcends its textual configuration. It keeps in sight the update of literature teaching in high school (medium level). In order to achieve such goal, this research analyses theoretical tools developed by the Reception Aesthetics and the so called Empiric Science of Literature. It evaluates the opportunity of transferring those models to the space of the school, as an innovative pedagogical strategy capable of renewing the act of teaching. In such sense, this thesis intends to offer ways to deal with a still present tradition and the renewal proposals in the field of didactics concerning the literary phenomenon and its historiography.

\section{Key Words:}

Literature, Teaching, History of Literature 


\section{SUMÁRIO}

1. Introdução 9

2. História da literatura em questão 17

2.1. Um olhar crítico retrospectivo 17

3. Caminhos alternativos 36

3.1. Acentos sobre o leitor 36

3.2.O programa da Estética da Recepção 48

4. Modelos sistêmicos para a literatura 66

4.1. Historiografia literária no plural 66

4.2.O projeto da ciência empírica da literatura 75

5. Considerações finais 92

6. Referências bibliográficas 95 